\title{
Mediatization of Culture in the Discourse of Modern Kazakh Media
}

\author{
D.O. Baigozhina ${ }^{1}$, N.I. Klushina ${ }^{2}$, S.Sh. Takhan ${ }^{3}$ \\ ${ }^{1}$ Eurasian National University n.a. L.N. Gumilyov \\ 2, Satpaeva str., 010000 Astana, Kazakhstan \\ ${ }^{2}$ Moscow State University n.a. M.V. Lomonosov \\ 9, Mohovaja str., 125009 Moscow, Russia \\ ${ }^{3}$ Eurasian National University n.a. L.N. Gumilyov \\ 2, Satpaeva str., 010000 Astana, Kazakhstan
}

\begin{abstract}
The concept of mediatization in modern social sciences leads to a new understanding of the role of media in society and culture. Within the framework of this concept, media appears not as an intermediary between society, its culture and socially significant information, but as a structural element of society and culture itself (T. Adorno, M. Castells, N. Couldry, S. Hjarvard, F. Krotz, S. Livingstone, W. Lippmann, N. Luhmann, M. McLuhan, P. Lazarsfeld, R. Merton, K. Popper, S. Zizek). The relevance of our study is due to the urgent need to investigate the effects of mediatization associated with its increasingly global nature. We hypothesise that in the process of mediatization of culture in the space of any national media discourse a new type of culture is created - media culture. The aim of this study is to show the formation of media culture on the example of the Russian language media discourse in Kazakhstan. The research is based on the linguistic concept of precedence (Yu.N. Karaulov, V.G. Kostomarov, D.B. Gudkov, V.V. Krasnykh) and the modern understanding of the typology of culture in Russian philosophy (N.B. Kirillova, V.V. Mironov and etc.). The study pursues the following goals: to identify precedent phenomena, which we define as minimized texts of culture, in the headers of the most widely circulated Russian language publications in Kazakhstan; to analyse precedent onyms associated with the classical (elitist) or mass culture; to consider phraseological units as markers of popular culture. On the basis of the analysis of precedents and phraseological units used in the dominant positions of the Russian language media discourse in Kazakhstan, we conclude that media culture is formed in the process of mediatization of elite, mass and folk culture through precedents and phraseological units. Media culture is a special, integral type of modern culture that combines elements of all types of cultures (elite, mass and folk) and is replicated through mass media in society. It consolidates society on the basis of general media knowledge.
\end{abstract}

Keywords: mediatization, media discourse, Kazakhstan media, media culture, precedent phenomena, phraseological units, culture codes

\section{For citation:}

Baigozhina, Dana O., Natalia I. Klushina and Serik Sh. Takhan. (2019) Mediatization of Culture in the Discourse of Modern Kazakh Media. Russian Journal of Linguistics, 23 (3), 784-801. doi: 10.22363/2312-9182-2019-23-3-784-801. 


\title{
Медиатизация культуры в дискурсе современных казахстанских медиа
}

\author{
Д.О. Байгожина ${ }^{1}$, Н.И. Клушина ${ }^{2}$, С.Ш. Тахан ${ }^{3}$ \\ ${ }^{1}$ Евразийский национальный университет имени Л.Н. Гумилева \\ 010000, Казахстан, Астана, ул. Сатпаева, 2 \\ ${ }^{2}$ Московский государственный университет имени М.В. Ломоносова \\ ул. Моховая, д. 9, Москва, 125009, Россия \\ ${ }^{3}$ Евразийский национальный университет имени Л.Н. Гумилева \\ 010000, Казахстан, Астана, ул. Сатпаева, 2
}

\begin{abstract}
Аннотация
Концепция медиатизации в современной науке приводит к новому пониманию роли медиа в обществе и в культуре. Медиа предстают в рамках данной концепции не как посредник между обществом, его культурой и социально значимой информацией, а как структурный элемент самого общества и культуры (T. Adorno, M. Castells, N. Couldry, S. Hjarvard, F. Krotz, S. Livingstone, W. Lippmann, N. Luhmann, M. McLuhan, P. Lazarsfeld, R. Merton, K. Popper, S. Zizek). Актуальность нашего исследования обусловлена назревшей необходимостью изучить эффекты медиатизации, связанные с ее все более глобальным характером. В процессе медиатизации культуры в пространстве любого национального медиадискурса создается новый тип культуры - медиакультура. Цель исследования показать на примере русскоязычного медиадискурса Казахстана, как происходит формирование медиакультуры. Исследование базируется на отечественной лингвистической концепции прецедентности (Ю.Н. Караулов, В.Г. Костомаров, Д.Б. Гудков, В.В. Красных и др.) и на современном философском понимании в российской науке типологии культуры (Н.Б. Кириллова, В.В. Миронов и др.). В исследовании ставились задачи: выявить в заголовочных комплексах наиболее тиражных русскоязычных изданий Казахстана прецедентные феномены, которые нами понимаются как свернутые тексты культуры; проанализировать прецедентные онимы с точки зрения их апелляции к классической (элитарной) или массовой культуре; рассмотреть фразеологизмы как маркеры народной культуры. По результатам анализа делается вывод о том, что медиакультура формируется в процессе медиатизации элитарной, массовой и народной культуры посредством прецедентов и фразеологизмов. Она представляет собой особый, интегральный тип современной культуры, совмещающей в себе элементы всех типов культур (элитарной, массовой и народной) и тиражирующейся через СМИ в общество, и выполняет важную функцию консолидации социума на основе общего медийного знания.
\end{abstract}

Ключевые слова: медиатизачия, медиадискурс, казахстанские СМИ, медиакультура, прецедентные феномены, коды культуры

\section{Для цитирования}

Байгожина Д.О., Клушина Н.И., Тахан С.Ш. Медиатизация культуры в дискурсе современных казахстанских медиа // Russian Journal of Linguistics. 2019. Т. 23. No 3. С. 784-801. doi: 10.22363/2312-9182-2019-23-3-784-801.

\section{1. Введение}

В современной лингвистике произошло несколько кардинальных поворотов, связанных с обновлением теоретической и методологической базы исследований (повороты когнитивный, коммуникативно-прагматический, дискурсологический), а также «медийный поворот» (Ст. Гайда), связанный с выдвижением в центр лингвистических наблюдений такого объекта, как язык в медиа, в том числе в циф- 
ровых медиа и в интернете. До настоящего времени исследования языка СМИ проводились в рамках функциональной стилистики, язык СМИ описывался как публицистический (газетно-публицистический) функциональный стиль - один из 5 стилей русского литературного языка, наравне с официально-деловым, научным, разговорным и литературно-художественным функциональными стилями. В рамках функциональной стилистики была описана структура публицистического стиля, выявлены два его подстиля - собственно-публицистический и информационный, сформирована типология публицистических и информационных жанров. В начале XXI века с изменением экстралингвистических условий формирования стилей литературного языка (возникновение интернета и цифровизация общественной деятельности) и выдвижением языка СМИ в центр исследований функциональной стилистики (вместо языка художественной литературы) возникает острая необходимость в обновлении и создании новых методологических принципов и понятийного аппарата для понимания языковых процессов, вызванных технологическими причинами. Таким образом, медийный поворот в лингвистике стал импульсом к формированию новых научных областей - медиалингвистики (Добросклонская 2008 и др.), медиастилистики (Клушина 2018 и др.), интернетлингвистики (Тошович 2015 и др.). Данные научные дисциплины находятся в соотношении части и целого: интернет-стилистика является активно развивающейся областью медиастилистики, а медиастилистика, в свою очередь, в значительной мере входит в состав медиалингвистики, но не совпадает с ней, поскольку опирается на категориальный аппарат и методологию общей теории стилистики и репрезентирует ее закономерное развитие в информационную эпоху.

Именно медийным поворотом обусловлена актуальность нашего исследования, которое посвящено изучению медиатизации как важнейшего стилистического процесса, влияющего на формирование и функционирование не только любого национального медиадискурса, но и глобального дискурса медиа.

Цель исследования - показать на примере казахстанских СМИ, как в процессе медиатизации культуры формируется новый тип культуры, а именно медиакультура, составляющая «матрицу культуры» (Шеченко 2018) в современном медиатизированном социуме. Новизна и теоретическая значимость исследования обусловлены новым, стилистическим подходом к пониманию процесса медиатизации. Медиатизация культуры с точки зрения стилистики - это «создание зон пересечения медиа и культуры» (Клушина 2018), т.е. создание особого субдискурса культуры, в котором интегрируются разные типы культуры культура традиционная, элитарная и массовая.

\section{2. Материал, методология и методы исследования}

Эмпирической базой для исследования послужили медиатексты русскоязычных СМИ Казахстана. Для анализа нами были выбраны заголовочные комплексы статей, поскольку заголовки являются сильными позициями текста и оказывают непосредственное влияние на восприятие читателя. Современный читатель в поставляемом медиа информационном потоке ориентируется по заголовкам и часто 
составляет себе информационную картину дня исключительно по заголовочным комплексам, совокупность которых формирует у адресата фоновые медийные знания, вполне достаточные в условиях стремительного обновления информации для понимания происходящего в стране и мире. Поэтому именно заголовки представляют собой ключевые тематические и экспрессивные доминанты, организующие медиадискурс, и воспринимаются как самостоятельный субдискурс. Необходимо также учитывать, что с возникновением цифровых технологий функции заголовков меняются: заголовки часто утрачивают связь с репрезентируемыми ими медиатекстами и получают самостоятельную роль в интернет-коммуникации в качестве заголовков-анонсов, которые читатель разворачивает в текст, кликая на них только при желании узнать детали сообщения или из-за любопытства. Отсюда возникает проблема кликбейта и утраты традиционной связи заголовка с медиатекстом. В условиях конкурентности медиа и их медийных продуктов (медиатекстов) заголовочная политика изданий сближается с маркетинговыми стратегиями, и поэтому сегодня заголовки рассматриваются как элемент продвигающих и продающих коммуникаций (пиар и рекламы). Нередко заголовки дает не автор-журналист, а редактор или специальный отдел в редакции, поэтому современный заголовок часто не учитывает авторскую интенцию и начинает выполнять особую прагматическую функцию (в дополнение к традиционным стилистическим функциям). Все сказанное позволяет нам рассматривать заголовки как самостоятельные тексты, организованные в заголовочный субдискурс медиадискурса, они активно участвуют в формировании матрицы медиакультуры, репрезентируемой в СМИ.

Нами проанализированы прецедентные феномены и фразеологизмы, включенные в заголовочные комплексы медиатекстов разных жанров, но объединенные общей темой — темой культуры. Материалом послужили те СМИ, которые в трехчастной типологической структуре медиа (качественные, массовые и желтые издания) обозначаются как массовые СМИ. Именно в данном типе медиа распространен «культурный» контент, который практически не релевантен для нишевых и специализированных изданий (например, в области экономической, научной, RT- и IT-журналистики и т.п.). Ориентация на максимально широкую аудиторию данного типа изданий способна обеспечить наибольший (в количественном измерении) прагматический эффект.

Для сбора эмпирического материала, таким образом, были выбраны наиболее популярных и тиражных русскоязычных СМИ Казахстана (газеты «Экспресс К», «Казахстанская правда», «Айкын», «Курсивъ» и др.) за 2017-2018 г. Дадим краткую характеристику анализируемых изданий:

1. «Айкын». Это республиканская общественно-политическая газета. Выпускается 4 раза в неделю. Она в информационную повестку включает темы политики, экономики, общественной жизни, спорта, культуры и т.п. Территория распространения: Республика Казахстан. Тираж 40 000. Еженедельный тираж 160000.

2. «Экспресс К». Ежедневная общественно-политическая республиканская газета Казахстана. Круг читателей - активная, деловая часть населения. Бумажная 
версия «Экспресс К» выходит пять раз в неделю (вт., ср., чт., пт., сб.). Интернетверсия обновляется круглосуточно. Газета в информационную повестку включает темы и рубрики: социум (экспертиза, человеческий фактор, окражающая среда, острый угол, на местах, диалог, помощь), происшествия (розыск, ЧС, сводка, фемида), жизнь (здоровье, праздник, профессия, экскурсия, образование, увлечение, фауна, память), мир (горячая точка, проишествия, политэкономия), политика (президент, форум, визит, ведомство), экономика (ресурсы, промышленность, сельское хозяйство, строительство и транспорт, финансы и рынки, бизнес), культура (кино, литература, музыка, шоубизнес, мода, экспозиция, сцена), спорт (вокруг спорта, репортаж, чемпионат, новости), наука (открытия, иследование, неизведанное, технологии, космос). Тираж: еженедельный - 51505.

3. «Литер». Ежедневная республиканская общественно-политическая газета. Основные рубрики: политика, общество, экономика, спорт, культура, наше государство, актуальное. Тираж ежедневно: 30000 экз. Распространение: по всей территории Республики Казахстан по подписке и в розницу. Периодичность: 4 раза в неделю (вторник, среда, пятница, суббота).

4. «Казахстанская Правда». Общенациональная ежедневная газета, главный источник официальной и деловой информации в республике. Тираж 100 тысяч экземпляров. Основные рубрики: Президент, политика, экономика, проишествия, общество, технологии, культура, спорт, мир.

5. «Комсомольская правда. Казахстан». Республиканская общественно-политическая газета. Выходит как республиканская вкладка в российскую газету «Комсомольская правда». Тираж газеты: 450000 экземпляров в месяц, периодичность: вторник, четверг, пятница. Электронные подписчики на e-mail, которые получают газету в формате PDF, - более 65000 человек по всему Казахстану, и с каждым днем эта цифра увеличивается. Контент: на страницах газеты освещаются политические и экономические события в стране и за рубежом, культурная и спортивная жизнь республики, поднимаются актуальные проблемы и вопросы, социальнозначимые темы. Основные рубрики: политика, экономика, общество, история, культура, красота/здоровье, спорт, афиша. Распространяется во всех областях РК.

6. «Курсивъ». Республиканский деловой еженедельник для экономически активного населения Казахстана. Тираж: 12500 экземпляров. Рубрики: политика, экономика, власть и бизнес, финансы, компании и рынки, общество, авто, культура и стиль, тенденции и исследования.

Как видим, выбор изданий обусловлен следующими экстралингвистическими факторами: высокая тиражность, широкий охват целевой аудитории, тематическая специфика, география распространения и др. Данные издания, таким образом, являются массовыми, включают специальные тематические рубрики, в которых публикуются материалы, репрезентирующие культурные события страны, и охватывают все регионы Казахстана. Это позволяет говорить о том, что медиатизация культуры, происходящая посредством данных СМИ и формирующая в них особый субдискурс культуры, будет транслирована практически на всю аудиторию страны и поддерживать в казахском обществе традиционные и новые культурные коды. 
Методом сплошной выборки была создана база данных, включающая примеры употребления в медиатекстах прецедентных феноменов (в частности, прецедентных онимов) и фразеологизмов, которые мы рассматриваем как вербальную репрезентацию современных культурных кодов. Эмпирическая база составила около 500 примеров, что позволяет говорить о репрезентативности и достоверности нашего исследования. Прецедентные феномены не только апеллируют к текстам культуры, но и сами по себе являются свернутыми текстами культуры. Реализуясь в медиадискурсе в свернутом (можно даже сказать, закодированном) виде, данные феномены выполняют важную просветительскую и культуроформирующую функцию инкорпорирования в общественное сознание символов высокой культуры. Фразеологизмы мы включили в эмпирическую базу исследования в качестве маркеров традиционной народной культуры, выполняющих в медиадискурсе ту же функцию, что и прецедентные феномены.

Нами была разработана методология анализа, релевантная целям и задачам проводимого исследования. Методология реализуется посредством следующего алгоритма последовательных шагов анализа:

1) опираясь на стратификацию современной культуры (Н.Б. Кириллова, В.В. Миронов, С.Г. Тер-Минасова и др.), в которой различается культура элитарная, традиционная и массовая, мы выделяем в исследуемых медиатекстах маркеры данных типов культуры - прецедентные феномены и фразеологизмы;

2) соотносим выявленные прецеденты и фразеологизмы с каждым типом культуры;

3) выделенные маркеры культуры классифицируем также в соответствии с их укорененностью в национальной культуре (казахской), русской культуре и мировой культуре, поскольку русскоязычный медиадискурс Казахстана отражает его полилингвальную культуру (отметим, что современная языковая политика Казахстана заключается в формировании трехъязычной языковой личности, владеющей казахским, русским и английским языками).

4) рассматриваем инкорпорирование в казахстанский медиадискурс выделенных нами культурных кодов и их взаимодействие.

В проведенном нами исследовании мы использовали стилистический метод контекстуального анализа и метод интерпретационного анализа для декодирования культурных кодов в медиатексте, с учетом экстралингвистических факторов. Также мы применяли метод стилистического толкования выбора вербального маркера культуры с функцией экспрессивизации медиатекста. В исследовании также были использованы элементы прагмастилистического метода (для понимания и объяснения перлокутивного эффекта) и лингвокультурологического метода анализа прецедентности и интертекстуальности в медиатекстах.

\section{3. Концепция медиатизации}

Медиатизация различных сфер общественной жизни (политики, культуры, экономики, науки и др.) - новое исследовательское направление в медиастилистике, которое по-новому формулирует вопросы, касающиеся влияния средств массовой информации на культуру и общество. В исследованиях по функциональ- 
ной стилистике данная проблема не затрагивалась. В рамках функциональной стилистики обсуждались вопросы вовлечения в публицистический стиль различных элементов других стилей как особенность данного незамкнутого стиля на фоне закрытых стилей русского языка (например, официально-делового). Впервые стилистическая роль медиатизации и сама медиатизация как стилистический феномен была освещена в монографическом исследовании «Медиастилистика» (Клушина 2018), которое является первой попыткой конституирования новой лингвистической области, возникшей как результат медийного поворота в лингвистике. «Медиатизация - это придание публичности различным сторонам социальной деятельности и вовлечение их в сферу общественных дискуссий, что может повлечь за собой широкий резонанс и, в конечном итоге, важнейшие изменения в общественной жизни и в общественном сознании. Медиатизация общественной жизни - важнейшая социальная функция современных СМИ. Вовлекая в свое пространство другие дискурсы и преобразуя их соотносительно собственных законов, медиадискурс тем самым способен описать все многообразие мира, сделать знание не столько «общеизвестным», как это считают некоторые исследователи медиадискурса, сколько общим, консолидирующим национальные социумы и макклюэновскую «глобальную деревню». Медиатизация обладает и стилистической значимостью. Зоны пересечения медиадискурса с другими институциональными дискурсами создают уникальную стилистическую ситуацию: в пространстве медиадискурса сосуществуют контексты из различных сфер деятельности. Но все эти контексты не просто сосуществуют как фрагменты внешнего мира — в едином пространстве медиадискурса фрагментарность внешней жизни преобразуется в целостный медиамир, в котором различные контексты призваны усиливать его достоверность, его реальность» (Клушина 2018).

Таким образом, концепция медиатизации оказалась необходимой и востребованной для понимания того, как посредством медиа вовлекаются в общественную жизнь различные институциональные сферы (политика, бизнес, культура, религия и др.), как они репрезентируются средствами массовой информации и - в конце концов - влияют на общественное сознание и нашу реальность. Например, освещение новостей во время предвыборной кампании оказывает влияние на политические взгляды людей; реклама влияет на потребительские предпочтения покупателей; рассказы о культурных событиях выполняют просветительскую функцию и сохраняют в социуме культурные коды.

Данная новая концепция имеет не только важное стилистическое значение, но и значение социальное. Медиатизация всех сторон общественной жизни, наступившая с развитием цифровых технологий, свидетельствует о том, что медиа перестали быть просто посредником в распространении информации (в концепциях Г. Макклюэна, Н. Лумана и др.). Медиа стали средой обитания, повседневностью для цифрового человека, который погружен в эту среду, влияет на нее и зависим от нее. Концепция медиатизации как раз и помогает выявить подобное влияние медиа на индивидуум и социум и обратное влияние человека на медиа и медиасреду. Результатом данного взаимодействия становится формирование 
и развитие нового, медиатизированного бытия человека. Социум приспосабливается к законам медиа, но и сами медиа преобразуются под воздействием общественных законов.

Таким образом, медиатизация связана с изменением понимания роли медиа в структуре общественной жизни. Это не означает, что традиционные вопросы, связанные с использованием медиа в качестве «передатчика» (медиума), уже не актуальны. Но это означает, что понимание важности средств массовой информации в современной культуре и обществе больше не может опираться на те объяснительные модели, которые предполагают, что средства массовой информации отделены от культуры и общества и что они обеспечивают только процесс посредничества («месседж», по Г. Макклюэну). Средства массовой информации это не просто технологии, которые организации или отдельные лица могут использовать или не использовать по своему усмотрению. Наличие средств массовой информации стало структурным условием для социальных и культурных практик, как в культурной сфере, так и в обществе в целом (Ливингстон, 2009). Средства массовой информации являются одновременно частью самой социальной и культурной сферы. Они представляет собой общую арену общественного обсуждения. Поэтому в современной медиалогии медиатизацию рассматривают как макросоциальный процесс (наравне с глобализацией), поскольку ее влияние отражается на развитии общества в целом (Дж. Маццолени). Медиатизация - это процесс, в котором социальные институты (не связанные со СМИ) должны адаптироваться к медийной логике, к медийным целям и ограничениям (Дж. Маццолени, В. Шульц, С. Хьярвард).

Таким образом, в нашем исследовани феномен медиатизации необходим для раскрытия механизма формирования медиакультуры в СМИ и посредством СМИ. Медиатизация для решения поставленных нами научных задач используется в двух аспектах: стилистическом (как способ формирования медиакультуры в медиадискурсе с помощью включения в него текстов и вербальных символов разных типов культур) и в социальном (как особый процесс институализации медиа и превращения медиа из посредника, канала связи между социальными сферами в самостоятельный институт, выполняющий консолидирующую, адаптирующую и собственно формирующую функции для развития общества в цифровую эпоху.

В своем исследовании мы рассматриваем частный аспект медиатизации медиатизацию культуры в казахстанских СМИ.

\section{4. Прецедентность как маркер медиатизации культуры}

Медиатизация культуры создает в рамках медиадискурса особый субдискурс, который мы условно называем культурный медиадискурс (Клушина, 2018). Его роль - сохранение национальной и всемирной культурной традиции в современном информационном обществе, трансляция культуры на широкую национальную (прежде всего) аудиторию, инкорпорирование мирового опыта в национальную картину мира, формируемую медиа, и - в итоге - укоренение ее в массовом 
сознании для консолидации социума и его просвещения. Мы опираемся на понимание современными философами (Кириллова 2006, Миронов 2008 и др.) неоднородности культуры, в которой различают элитарную/высокую культуру, народную/традиционную культуру и культуру массовую (поп-культуру, масскульт). Эта типология культуры базируется в том числе и на семантике культуры: народная культура сохраняет традицию (сказки, предания, пословицы, фразеологизмы), элитарная культура производит новые смыслы, а массовая культура тавтологична (она лишь тиражирует образы народной и элитарной культуры).

Медиатизация культуры происходит через прецедентные культурные феномены и фразеологию, которые, попадая в медиа, становятся свернутыми текстами культуры и узловыми точками в картине мира и в формируемом медиа массовом сознании. Особенности трансформации массового сознания под воздействием медиадискурса и возможность выделения особого типа - массмедийного сознания описаны в монографии «Медиастилистика»: «Мы осмелимся утверждать, что медиа не манипулируют массовым сознанием, а формируют свой, особый тип сознания - медийное, которое становится основой массового сознания. В доинформационную эпоху человек получал информацию из разных источников из книг, фильмов, путешествий, из взаимодействия и общения с другими людьми, т.е. опытным, а не виртуальным путем. Добытую информацию необходимо было осмыслить и отрефлексировать. Таким образом у человека вырабатывалась привычка к личному осознанию внешнего мира и набирался багаж из собственных переживаний. Индивидуальный опыт (чувственный и интеллектуальный) доставался с трудом и являлся основой индивидуальности. В информационном обществе медиа, как и любые достижения технического прогресса, облегчают труд (в данном случае - именно интеллектуальный) и заменяют личную рефлексию на полуфабрикаты готовых интерпретаций. Поэтому мы говорим о сращивании медийного сознания с массовым. Массовое сознание отказывается от личного, индивидуального опыта в пользу тривиального, тиражируемого, массового» (Клушина 2018: 84). Таким образом, через репрезентацию прецедентных феноменов и фразеологизмов и других культурных кодов в СМИ человек информационной эпохи приобщается к высокой и к традиционной культуре, включает их в когнитивную сферу своей личности.

В данном параграфе нашей статьи мы исследуем медиатизацию культуры через прецедентные феномены в современном казахстанском медиадискурсе с целью выявления особенностей и проблематики культурного казахстанского медиадискурса, который оказывает сильное воздействие на массовое сознание медийной аудитории Казахстана. В своем исследовании мы опираемся на концепцию прецедентности, разработанную Ю.Н. Карауловым, В.Г. Костомаровым, Д.Б. Гудковым, В.В. Красных и др. В казахской лингвистике над прецедентными феноменами работали исследователи Т. Коныров, Г.Б. Мадиева, Е. Керимбаев, Г.Х. Ихсангалиева, Н.Уали и др.

Прецедентные феномены дифференцируются на прецедентные онимы, прецедентные тексты, прецедентные ситуации/ события, прецедентные высказывания 
(В.В. Красных, 2003). Различаются универсальные и национальные прецедентные феномены (В.В. Красных, 2003). Мы исследуем прецеденты, которые представляют в медиадискурсе русскоязычных СМИ Казахстана феномены культуры, как глобальной, так и национальной. Спецификой казахстанского медиадискурса является тот факт, что в нем отражаются универсальные прецедентные феномены (относящиеся к мировой культуре), и национальные, которые, в связи с историческим семидесятилетним сосуществованием в границах единого государства СССР, репрезентируют апелляцию к двум национальным лингвокультурам - русской и казахской. Таким образом, первый вектор классификации и изучения прецедентных культурных феноменов связан с осью универсальности - национальной специифичности

универсальные прецеденты

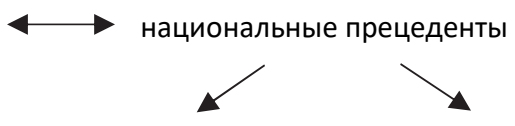

русские + казахские

Второй вектор изучения связан с различением в современной культуре элитарной культуры и массовой. Отсюда мы группируем отдельно прецедентные феномены, инкорпорирующие в медиадискурс элементы элитарной/классической культуры и элементы массовой/поп-культуры.

Рассмотрим примеры прецедентных феноменов, циркулирующих в русскоязычном медиадискурсе Казахстана.

Мы выделяем три типа прецедентов.

- Универсальные прецедентные феномены, к которым относим прецеденты классической мировой культуры, известные всему мровому соообществу:

(1) «Казахский Моцарт» (про молодого казахстанского музыканта Рахат-Би-Абдысагин, который покорил мир);

(2) Казахстанскую Мадонну оценят в Париже (о казахстанке Светлане МеликНубаровой, которая получила приглашение участвовать в престижном Международном конкурсе фотографов в Париже. Ее оригинальные работы, воспевающие материнство, вызвали огромный интерес у европейских экспертов и критиков);

(3) Казахский Пикассо (о казахском художнике Салихитдине Айтбаеве, который был ярким представителем шестидесятников. Искусствоведы не без оснований прозвали его казахстанским Пикассо. В его творчестве легко прослеживаются мотивы работ испанского и французского художника, но с казахским национальным колоритом - таков уникальный, узнаваемый стиль знаменитого казахстанца);

(4) Возьмите Моцарта с собой... (Моцарт - австрийский композитор и музыкантвиртуоз. Один из самых популярных классических композиторов, Моцарт оказал большое влияние на мировую музыкальную культуру);

(5) Под звуки скрипки Страдивари (Страдивари - мастер струнных инструментов, ученик Николо Амати) и др.

Универсальные прецеденты, апеллирующие к высокой культуре в русскоязычном медиадискурсе Казахстана используются в доминантных позициях 
дискурса (в заголовочных комплексах) и не только привлекают внимание адресата, но и формируют в общественном сознании устойчивые связи с мировой классикой (живопись, музыка, литература и т.п.), тем самым включая казахского читателя в мировой культурный процесс.

Особо следует отметить умелую корелляцию мировой культуры с казахстанской через устойчивую и частотную модель: казахстанский/-ая + оним, репрезентирующий классический прецедентный феномен (см. примеры (1)-(3)).

- Национальные прецедентные феномены (принадлежащие как к русской лингвокультуре, так и казахской)

\section{Русские:}

(6) Средь шумного бала: первая скрипка - об особенностях работы в оркестре;

(7) Он памятник себе воздвиг...;

(8) Чеховские посиделки;

(9) И смех, и слезы, и кино;

(10) Герои нашего времени и др.

\section{Казахские:}

(11) «Золотой человек» шагает по планете (Золотой человек - это Алтын адам, сакский воин. Воин, облаченный в золотой костюм с алыми вставками и высокий конусообразный шлем, стал государственным символом страны, саки жили в V-VI веке);

(12) Культегин в столице (Культегин - политический и военный деятель Второго тюркского каганата, соправитель Бильге-кагана, сын Кутлуг-Эльтериш-кагана, жил в конце VII — первой половине VIII в.в., история казахов);

(13) По следам Коркыта (Коркыт - легендарный тюркский поэт-песенник и композитор IX века, выходец из степей вдоль реки Сыр-Дарья);

(14) Коркыт и мелодии Великой степи;

(15) От Балкан до Великой степи (Балканы - Балканский полуостров, расположен на юго-востоке Европы. Великая степь - земля казахов);

(16) «Акбаян» в Эдинбурге («Акбаян» - спектакль по мотивам лиро-эпической драмы казахского народного писателя Габита Мусрепова «Козы Корпеш Баян Сулу») и др.

Как показывают наши примеры, в казахстанском медиадискурсе тесно переплетаются элементы русской классической культуры и казахской. Русские прецедентные феномены в основном принадлежат классической литературе, являющейся обязательной для изучения в школах, этим можно объяснить частотность их включения в заголовки статей, к тому же они не требуют декодирования.

Феномены казахстанской национальной классической культуры также составляют ядро прецедентности в русскоязычном медиадискурсе страны и выполняют просветительские функции в национальной лингвокультуре.

- Прецеденты массовой культуры, которые апеллируют к онимам глобализированной поп-культуры:

(17) Козы-Корпеш и Мэрилин Монро (Козы-Корпеш — казахская лиро-эпическая поэма XIII-XIV веков, записана в середине XIX века, Мэрилин Монро американская киноактриса, секс-символ 1950-х годов, певица и модель);

(18) Малефисента великой степи (Малефисента - современный фильм, в главной роли Анджелина Джоли, великая степь - степь, где кочевали казахи); 
(19) Казахстанский Гарри Поттер мечтает стать проводником («Гарри Поттер» - современный фильм по роману английской писательницы Джоан Роулинг, 11-летний Жалгас Нурлыбек, победивший тяжелую болезнь, на фотосессии любил быть Гарри Потером).

Данные примеры демонстрируют отмеченную при использовании прецедентов классической культуры тенденцию к корелляции онимов массовой культуры с казахскими кодами культуры, что способствует инкорпорированию в медиадискурс Казахстана элементов глобальной поп-культуры и погружению их в национальный контекст.

В рассматриваемом нами процессе медиатизации массовой культуры необходимо выделить в качестве самостоятельного сегмент медиадискурса, который включает в себя прецедентные высказывания российской поп-культуры, наиболее частотными из которых являются прецеденты из песен российской эстрады. Например:

(20) Какой портрет, какой «Алаш» («Какой портрет, какой пейзаж» взято из эстрадной песни, Алаш - существовавшее в годы Гражданской войны самопровозглашенное казахское государство, под управлением правительства «Алаш-Орды»);

(21) Какой портрет, какой визаж;

(22) Мы поедем, мы помчимся!

(23) Старая сказка о главном;

(24) Миллион Алле роз!

(25) Их ирония судьбы и др.

Также особый пласт прецедентных феноменов казахстанского медиадискурса сформирован прецедентами-советизмами, т.е. кодами советской культуры, которую с позиций сегодняшнего дня можно рассматривать как особую диффузную область между высокой/ элитарной культурой и поп-культурой, поскольку советская культура зачастую апеллирует к высоким смыслам (особенно, в той части культуры, которая описывает героику Великой Отечественной войны). Например:

(26) В их сердиах набат: Сталинград! Сталинград!;

(27) Ничто не забыто, никто не забыт;

(28) Как закалялся стиль;

(29) В огне брода нет;

(30) А вазы я попрошу остаться («А вас я попрошу остаться» — взято из фильма «Семнадцать мгновений весны»);

(31) Сильные духом и др.

Таким образом, наше исследование показывает, что в казахстанском субдискурсе культуры наиболее частотны прецеденты, обеспечивающие связь с общемировым культурным достоянием (Вход к да Винчи свободный; Ромео и вендетта; От Шекспира до колдовства; Казахский Моцарт и др.), с народной культурой (Коркыт и мелодии Великой степи и др.), а также с русской культурой (Oн памятник себе воздвиг...; Чеховские посиделки и др.).

Общемировые и русские прецеденты высокой культуры, транслируемые через СМИ, выполняют важную просветительскую функцию в современном казахстанском обществе. Прецеденты национальной культуры сохраняют народную тради- 
цию и национальную специфику медиадискурса и картины мира в целом. Прецеденты массовой культуры выполняют функцию консолидации социума, включения его в глобальный контекст, но при этом теряется просветительская функция медиадискурса культуры.

\section{5. Фразеологизмы и их роль в медиатизации народной культуры}

Современные исследователи прецедентные феномены понимают довольно широко, относя к ним в том числе и фразеологию (на основании ее воспроизводимости и устойчивости). Таким образом, в российской научной традиции сосуществуют 2 точки зрения на прецедентность. В узком понимании к прецедентным феноменам относят только имена, высказывания, тексты и ситуации, в широком - к ним добавляется и фразеология.

Медиатизация фразеологизмов выполняет важную функцию сохранения народной мудрости и народных образов в массовом сознании. Казахстанский русскоязычный медиадискурс демонстрирует сильную тенденцию к использованию фразеологизмов в доминантных позициях. Причем фразеологизмы используются как в полной, так и в усеченной форме, например:

(32) Поматросил и бросил;

(33) Не в свои сани;

(34) Гора с плеч;

(35) Быка за рога;

(36) Век живи, век учись! и др.

Но наиболее частотны трансформированные фразеологизмы в функции языковой игры, например:

(37) Пух и крах;

(38) Погром среди ясного неба;

(39) Старый дракон борозды не портит;

(40) Береги жесть смолоду;

(41) Ума нет, считай - коллега;

(42) Арт костей не ломит;

(43) Как сюр в масле и др.

Наше исследование показывает, что фразеологизмы, встречающиеся в русскоязычных СМИ Казахстана, связаны прежде всего с русской народной культурой, что опять-таки отражает тесную связь казахской и русской культур, продиктованную экстралингвистическими факторами - общее советское прошлое. Этим же фактором объясняется частотное использование в русскоязычных СМИ Казахстана кодов и символов (в том числе трансформированных) русских народных сказок (напр., «Жили-были 3 невестки» и т.п.).

Подчеркнем, что фразеологизмы и другие коды народной культуры часто используются в заголовочных комплексах, поскольку несут экспрессивно-стилистическую информацию, помимо информации семантической, и тем самым они организуют пространство медиадискурса, закрепляются в массовом сознании социума, сохраняя связь с русской и мировой культурой. 


\section{6. Выводы}

Мы выявили в современной медиакультуре казахстанских СМИ использование в доминантных позициях медиадискурса прецедентов и фразеологизмов, репрезентирующих коды высокой классической культуры (универсальной классической культуры, национальной русской культуры, национальной казахской культуры), коды массовой культуры и коды культуры народной. Наше исследование медиатизации культуры позволяет сделать выводы о том, что медиа не просто транслируют коды классической, народной или массовой культуры, но и создают особый тип культуры - медиакультуру, которая переплавляет в себе различные коды и символы в единый медийный вариант современной культуры. Это позволяет говорить о медиакультуре как сложном феномене, кумулирующем в себе различные типы культуры, что противоречит устоявшемуся пониманию медиакультуры как синонима массовой, низкой культуры. По мнению Н.Б. Кирилловой, медиа - не просто набор технологий для распространения сообщений, это среда, где создаются, оформляются и передаются разные культурные коды и символы (Кириллова, 2006). Переплетение всех отмеченных кодов создает матрицу медиакультуры (Шевченко, 2018), которая, в свою очередь, формирует общественное сознание. Таким образом, в современном казахстанском субдискурсе культуры в результате медиатизации формируется особое коммуникативное пространство медиакультуры, с новой системой ценностей и сплетением не только кодов разных типов культур (традиционной, элитарной и массовой), но и разных национальных культур (казахской и русской).

Медиатизация нами понимается не только как социальный процесс, связанный с экстралингвистическими особенностями медиакоммуникации, когда практически все сферы социальной жизни представлены в том или ином виде в пространстве медиа через сайты, СМИ и соцсети, но и как стилистический вектор современного развития языка и культуры в медиа. Стилистика является важнейшей на сегодня интегративной гуманитарной наукой, в которой тесно переплетаются актуальные когнитивные, филологические, дискурсивные, прагматические и другие исследования. Выбор того или иного стилистического средства для репрезентации действительности всегда когнитивно и дискурсологически обусловлен. Поэтому формирование медиакультуры не линейный процесс, а стилистически обусловленный. Медиатизация культуры имеет различные эффекты. В нашем исследовании мы отметили важнейшие из них: консолидация общества на основе медийного знания, сохранение культурных ценностей национальной культуры, взаимопроникновение культур в едином национальном медиапространстве, интеграция в глобальный культурный контекст. Наше исследование позволяет раскрыть лингвистический механизм медиатизации культуры, показать полифункциональность процессов медиатизации, а также ввести концепцию медиатизации в категориальный аппарат формирующейся новой области стилистики медиастилистику.

() Д.О. Байгожина, Н.И. Клушина, С.Ш. Тахан (2019) cc) creative

https://creativecommons.org/licenses/by/4.0/ 


\section{СПИСОК ЛИТЕРАТУРЫ / REFERENCES}

Байгожина Д.О. Медиакультура в исторических изменениях // Вестник КазНУ имени аль-Фараби. Серия журналистика. 2018. № 1 (47). C. 170-178. [Baigozhina D.O. (2018) Mediakul'tura $\mathrm{v}$ istoricheskikh izmeneniyakh. Vestnik KazNU imeni al'-Farabi. Seriya zhurnalistika, 1 (47), 170-178. (In Kazakh)]

Гудков Д.Б. Теория и практика межкультурной коммуникации. М.: Гнозис, 2003. 288 с. [Gudkov, D.B. (2003). Teoriya i praktika mezhkulturnoy kommunikatsii. Moscow: Gnozis. (In Russ.)]

Добросклонская Т.Г. Медиалингвистика: системный подход к изучению языка СМИ. М.: Флинта: Наука, 2008. 264 с. [Dobrosklonskaya, T.G. (2008). Medialingvistika: sistemnyiy podhod k izucheniyu yazyika SMI. Moscow: Flinta: Nauka. (In Russ.)]

Добросклонская Т.Г. Медиадискурс как объект лингвистики и межкультурной коммуникации // Вестник Московского университета. Серия 10: Журналистика. 2006. № 2. С. 20-33. [Dobrosklonskaya, T.G. (2006). Mediadiskurs kak ob'ekt lingvistiki i mezhkulturnoy kommunikatsii. Vestn. Mosk. unta. Ser. 10. Zhurnalistika, 2, 20-33. (In Russ.)]

Жижек С. Киберпространство, или Невыносимая замкнутость бытия // Искусство кино. 1998. № 1. C. 119-128. [Zizek, Slavoj. (1998). Kiberprostranstvo, ili Nevyinosimaya zamknutost byitiya. Iskusstvo kino, 1, 119-128. (In Russ.)]

Жижек С. Возвышенный объект идеологии. М.: Художественный журнал, 1999. 114 с. [Zizek, Slavoj (1999). Vozvyishennyiy ob'ekt ideologii. Moscow. (In Russ.)]

Иванова М.В., Клушина Н.И. Нормы в массмедиа: когнитивный аспект // Вопросы когнитивной лингвистики. 2018. № 2. С. 5-12. [Ivanova M.V., Klushina, N.I. (2018). Normy v massmedia: kognitivnyy aspect. Voprosy kognitivnoy lingvistiki, 2, 5-12. (In Russ.)]

Караулов Ю.Н. Роль прецедентного текста в структуре и функционировании языковой личности // Научные традиции и новые направления в преподавании русского языка и литературы: Доклады советской делегации на VI конгрессе МАПРЯЛ. М., 1986. С. 105-123. [Karaulov, Yu.N. (1986). Rol' pretsedentnyih testov v strukture i funktsionirovanii yazyikovoy lichnosti. Nauchnyie traditsii i novyie napravleniya v prepodavaniya russkogo yazyika i literaturyi. Moscow. (In Russ.)]

Карасик В.И. Языковой круг: личность, концепты, дискурс. Волгоград: Перемена, 2002. 477 с. [Karasik, V.I. (2002). Yazyikovoy krug: lichnost, kontseptyi, diskurs. Volgograd: Peremena. (In Russ.)]

Кастельс М. Информационная эпоха: экономика, общество и культура. М.: ГУ ВШЭ, 2000. 608 c. [Kastels, M. (2000). The Information Age: Economy, Society and Culture. Moscow.: GU VShE]

Кириллова Н.Б. Медиакультура: от модерна к постмодерну. М.: Акад. проект, 2006. 448 с. [Kirillova, N.B. (2006). Mediakultura: ot moderna k postmodernu. Moscow: Akad. Proekt. (In Russ.)]

Клушина Н.И. Медиастилистика. М., 2018. 184 с. [Klushina, N.I. (2018). Mediastilistika. Moscow: Flinta. (In Russ.)]

Клушина Н.И. Культура в медиапространстве: структура и эффекты // Масс-медиа и массовые коммуникации: статус научных и учебных дисциплин: Первый Междунар. науч. коллоквиум. Белгород, 26-27 сентября 2013 г.: сб. науч. работ. Белгород, 2013. С. 37-42. [Klushina, N.I. (2013). Kultura v mediaprostranstve: struktura i effektyi. Mass-media i massovyie kommunikatsii: status nauchnyih i uchebnyih distsiplin: Pervyi Mezhdunar. nauch. kollokvium, Belgorod, 26-27.09.2013, 37—42. (In Russ.)] 
Клушина Н.И. Дискурс-анализ и стилистика: интегративные методы исследования медиа коммуникации // Вестник Российского университета дружбы народов. Серия: Лингвистика. 2016. T. 20. № 4. C. 78-90. [Klushina, N.I. (2016). Diskurs-analiz i stilistika: integrativnyye metody issledovaniya media kommunikatsii. Vestnik Rossiyskogo universiteta druzhby narodov. Seriya: Lingvistika = Russian Journal of Lingguistics, 4, 78-90. (In Russ.)]

Костомаров В.Г., Бурвикова Н.В. Как тексты становятся прецедентными // Русский язык за рубежом. 1994. № 1. C.73-76. [Kostomarov, V.G., Burvikova, N.V. (1994). Kak teksty stanovyatsya pretsedentnymi. Russkiy yazyik za rubezhom, 1, 73-76. (In Russ.)]

Красных В.В. Этнопсихолингвистика и лингвокультурология: курс лекций. М.: ИТДГК «Гнозис», 2002. 284 c. [Krasnyih, V.V. (2002). Etnopsiholingvistika i lingvokulturologiya: Kurs lektsiy. Moscow: ITDGK «Gnozis». (In Russ.)]

Лазарсфельд П., Мертон Р. Массовая коммуникация, массовые вкусы и организованное социальное действие // Массовая коммуникация в современном мире: методология анализа и практика исследований / М.М. Назаров. М., 1999. С. 138-149. [Lazarsfeld, P., Merton, R. (1999). Massovaya kommunikatsiya, massovyie vkusy i organizovannoe sotsialnoe deystvie. Massovaya kommunikatsiya v sovremennom mire: metodologiya analiza i praktika issledovaniy.Moscow, 138-149. (In Russ.)]

Липпман У. Общественное мнение. М.: Ин-т Фонда «Обществ. мнение», 2004. 384. [Lippman, Walter (2004). Public opinion. Moscow.: In-t Fonda «Obschestv. mnenie». (In Russ.)]

Луман Н. Реальность масс-медиа / пер. с нем. А.Ю. Антоновского. М.: Праксис, 2005. 256 с. [Luman, Niklas (2005). Realnost mass-media. Moscow: Praksis. (In Russ.)]

Луман Н. Медиа коммуникации. М.: Логос, 2005. 280 c. [Luman, Niklas (2005). Media kommunikatsii. Moscow.: Logos. (In Russ.)]

Макклюэн Г.М. Понимание медиа: внешние расширения человека. М.: Жуковский: Канонпресс, 2003. 464 с. [McLuhan, Herbert (2003). Understanding Media: The Extensions of Man. Moscow: Zhukovskiy: Kanon-press. (In Russ.)]

Миронов В.В. Средства массовой коммуникации как зеркало поп-культуры / Язык средств массовой информации. М.: Академический Проект, 2008. 315 с. [Mironov, V.V. (2008). Sredstva massovoy kommunikatsii kak zerkalo pop-kulturyi. Yazyik sredstv massovoy informatsii. Moscow: Akademicheskij Proekt (In Russ.)]

Поппер К. Открытое общество и его враги. М.: Феникс, Междунар. фонд «Культурная инициатива», 1992. 448 с. [Popper, Karl (1992). The Open Society and Its Enemies. Moscow: Mezhdunar. fond «Kulturnaya initsiativa» (In Russ.)]

Рогозина И.В. Функции и структура медиакартины мира // Методология современной психолингвистики: сб. статей. М., 2003. С. 121-137. [Rogozina, I.V. (2003). Funktsii i struktura mediakartinyi mira. Metodologiya sovremennoy psiholingvistiki: sb. statey. Moscow. 121-137. (In Russ.)]

Тахан С.Ш. Русские литературные традиции в очерках А. Букейханова (На материале публикаций в журнале «Сибирские вопросы») // Нёман: ежемесячный литературно-художественный и общественно-политический журнал (Беларусь). 2017. № 9. С. 132-140. [Takhan, S.SH. (2017). Russkiye literaturnyye traditsii v ocherkakh A. Bukeykhanova (Na materiale publikatsiy v zhurnale «Sibirskiye voprosy»). Noman: yezhemesyachnyy literaturno-khudozhestvennyy i obshchestvenno-politicheskiy zhurnal. Belarus, 9, 132-140. (In Kazakh)]

Тоффлер Э. Третья волна. М.: АСТ, 2002. 776 с. [Toffler, Alvin (2002). The Third Wave. Moscow: AST. (In Russ.)]

Тошович Б. Интернет-стилистика. М.: Флинта: Наука, 2015. 238 с. [Toshovich, Branko (2015). Internet-stilistika. Moscow: Flinta: Nauka. (In Russ.)] 
Третьякова О.В. Плюсы и минусы медиатизации правовой жизни общества // Вестн. Московского университета. Серия 10: Журналистика. 2011. № 4. C. 111-126. [Tretyakova, O.V. (2011). Plyusyi i minusyi mediatizatsii pravovoy zhizni obschestva . Vestn. Mosk. un-ta. Ser. 10. Zhurnalistika, 4, 111-126. (In Russ.)]

Черных А.И. Медиа и демократия. М.; СПб.: Университет. кн., 2011. 272 с. [Chernyih, A.I. (2011). Media i demokratiya. Moscow; SPb.: Universitet. kn. (In Russ.)]

Черных А.И. Социология массовых коммуникаций. М.: Издат. дом ГУ-ВШЭ, 2008. 451 с. [Chernyih, A.I. (2008). Sotsiologiya massovyih kommunikatsiy. Moscow: izdat. dom GU-VShE. (In Russ.)]

Черных А.И. Реальность «четвертой власти» // Социолог. журнал. 2008. № 1. С. 100-125. [Chernyih, A.I. (2008). Realnost «chetvertoy vlasti». Sotsiolog. Zhurnal, 1, 100 -125 (In Russ.)]

Шевченко Л.И. Символы модерной культуры в интертексте славянских медиа // Актуальные проблемы стилистики. 2018. № 4. C. 77-84. [Shevchenko, L.I. (2018). Simvoly modernoy kul'tury v intertekste slavyanskikh media. Aktual'nyye problemy stilistiki, 4, 77-84. (In Russ.)]

Adorno, Theodor (1991). The Culture Industry. Selected Essays on Mass Culture. London: Routledge.

Couldry, Nick (2008). Mediatization or mediation? Alternative understandings of the emergent space of digital storytelling. New Media Society, 10 (373), 373-391.

Fairclough, Norman (1995). Media discourse. New York, 1995.

Hjarvard, Stig (2008). The Mediatization of Society: A Theory of the Media as Agents of Social and Cultural Change. Nordicom Review, 2, 105-134.

Krotz, Friedrich (2007). The Meta-Process of "Mediatization" as a Conceptual Frame. Global Media and Communication, 3, 256-260.

Livingstone, Sonia (2009). On the mediation of everything: ICA presidential address 2008. Journal of communication, 59 (1), 1-18. DOI: 10.1111/j.1460-2466.2008.01401.x.

\section{Article history:}

Received: 07 January 2019

Revised: 20 February 2019

Accepted: 15 April 2019

\section{История статьи:}

Дата поступления в редакцию: 07 января 2019

Дата принятия к печати: февраля 202019

\section{Bionotes:}

DANA BAIGOZHINA is a PhD student of the Faculty of Journalism and Political Science at Gumilyov Eurasian National University. Her research interests embrace intercultural communication, mediatization of culture, information technologies and media education.

Contact information: e-mail: baigozhina777@mail.ru

NATALIA KLUSHINA is Doctor of Philology, Professor of the Department of Stylistics of the Russian Language Faculty of Journalism at Lomonosov Moscow State University. She is President of the Commission on Stylystics of the International Slavistic Committee. Her research interests cover stylistics, media stylistics and discourse analysis.

Contact information: e-mail: nklushina@mail.ru

SERIK TAKHAN is Doctor of Philology, Professor of the Faculty of Journalism and Political Science at Gumilyov Eurasian National University. Research interests: stylistics, history and theory of Russian and Kazakh journalism, intercultural communication and media discourse.

Contact information: e-mail: takhan_serik@mail.ru 


\section{Сведения об авторах:}

ДАНА ОНИРБЕКОВНА БАЙГОЖИНА - докторанТ факультета журналистики и политологии Евразийского национального университета им. Л.Н. Гумилева, старший преподаватель. Сфера научных интересов: межкультурная коммуникация, медиатизация культуры, информационные технологии, медиаобразование.

Контактная информация: e-mail: baigozhina777@mail.ru

НАТАЛЬЯ ИВАНОВНА КЛУШИНА - доктор филологических наук, профессор кафедры стилистики русского языка факультета журналистики МГУ им. М.В. Ломоносова, председатель Стилистической комиссии Международного комитета славистов. Сфера научных интересов: стилистика, медиастилистика, дискурсология.

Контактная информация: e-mail: nklushina@mail.ru

СЕРИК ШЕШЕНБАЕВИЧ ТАХАН - доктор филологических наук, профессор факультета журналистики и политологии Евразийского национального университета им. Л.Н. Гумилева. Сфера научных интересов: язык и стиль СМИ, история и теория русской и казахской публицистики, межкультурная коммуникация, теория и практика медиатекста.

Контактная информация: e-mail: takhan_serik@mail.ru 